Thorax (1974), 29, 425.

\title{
Regional lung function after pneumonectomy
}

\author{
D. RUSSELL HAL L ${ }^{1}$ \\ Regional Cardio-Thoracic Centre, Broadgreen Hospital, Liverpool
}

\begin{abstract}
Hall, D. R. (1974). Thorax, 29, 425-431. Regional lung function after pneumonectomy. Regional lung function was studied with xenon-133 in 10 patients with bronchial carcinoma before and again three to six months after pneumonectomy. It was found that ventilation and perfusion were often considerably reduced in the tumour-bearing lung and that the greater part of the cardiac output had apparently been diverted to the unaffected lung before operation. The regional distribution of ventilation and perfusion in the lung remaining after surgery was essentially unchanged from that measured in the same lung preoperatively and no different from the pattern seen in 10 normal volunteers.
\end{abstract}

Graham and Singer (1933), in their description of the first one-stage pneumonectomy for carcinoma, commented on the fact that ligation of the hilar vessels was not attended by the usual manifestations of a pulmonary embolus. Furthermore, after the operation the passage of the entire cardiac output through the residual lung did not appear to result in any deleterious effect. Increased experience showed that the physical activity of most subjects was little affected by pneumonectomy, young persons particularly being capable of high levels of physical performance (Peters et al., 1950). Cournand, Riley, Himmelstein, and Austrian in 1950 demonstrated in nine subjects that pulmonary artery pressures postoperatively were within normal limits at rest but were slightly raised following exercise. In a group of young subjects who had had a pneumonectomy four to six years previously, the same authors confirmed that pulmonary hypertension had not developed despite the years of increased pulmonary blood flow (Cournand, Himmelstein, Riley, and Lester, 1947). Mendelsohn, Zimmerman, and Adelman (1950) measured pulmonary artery pressures during pneumonectomy before and after ligation of the hilum and demonstrated that a small increase in pressure occurred after occlusion of the pulmonary vessels, although by the end of the operation the pressure had in most subjects returned to normal. Other workers, however, found some patients with a high preoperative pulmonary artery pressure who developed a further

\footnotetext{
1Present address: Cardio-Pulmonary Division, West Virginia Univer-
} sity Medical Center, Morgantown, West Virginia 26506, USA increase in pressure after pneumonectomy (Wiederanders, White, and Saichek, 1964). These latter patients tended to be older, to have respiratory symptoms, and to have abnormal lung function tests before surgery. In these subjects impaired adaptation to the postoperative increase in blood flow was attributed to reduced distensibility of the vascular bed in older patients and to vascular damage resulting from concomitant generalized lung disease (Harrison et al., 1958; Denolin, 1961). Invalidism and death from cor pulmonale were the results in those more severely affected. Preoperative assessment with balloon occlusion of the pulmonary artery on the side of the tumour was advocated to detect patients who might develop progressive pulmonary hypertension and who would benefit from less radical operation or in whom surgery was contraindicated (Carlens, Hanson, and Nordenström, 1951; Björk, 1953).

The development of regional lung function studies with radioactive gases has made available another means of studying the postoperative adaptation of the residual lung. In normal subjects, blood flow in the erect lung is maximal at the bases and falls off towards the apices (Ball, Stewart, Newsham, and Bates, 1962). West, Dollery, and Naimark (1964) have shown that this normal pattern of distribution is governed by the interplay of the effects of gravity, lung inflation, and the pulmonary arterial, venous, and alveolar pressures. In patients with mitral valve disease and left ventricular failure, increases in pulmonary arterial and venous pressures result in increased apical blood flow with an even distribu- 
tion of perfusion throughout the lung (Dollery and West, 1960; Ueda, Iio, and Kaihara, 1964; Dawson, Kaneko, and McGregor, 1965; Seaton, 1971). Similar effects on perfusion are seen when pulmonary blood flow is increased by exercise or by left to right cardiac shunts (Dollery et al., 1961; Bryan et al., 1964).

To see whether removal of one lung would alter the distribution of ventilation and blood flow in the other, regional lung function was studied in 10 patients before and after pneumonectomy for carcinoma.

\section{SUBJECTS}

Forty-nine patients with apparently resectable carcinoma were chosen from the surgical wards of the Regional Cardio-Thoracic Centre. After informed consent all were investigated preoperatively. Pneumonectomy was possible in 23 subjects and lobectomy in 14; 11 were inoperable and one patient refused surgery. Ten of the 23 pneumonectomy patients were available three to six months later for repeat studies. Of the other 13 subjects, six died after surgery, four suffered recurrence of their tumour, and three refused repeat investigation. No patient died of cardiac or respiratory failure. The mean age of the 10 patients studied was 56.5 (range 48-66) years. There were nine males and one female, eight left-sided resections and two right. Nine subjects were current smokers (eight cigarette and one pipe smoker) and there was one ex-smoker. Ten normal volunteers from among the hospital staff were studied similarly. They had a mean age of 30 (range 22-39) years, nine were males and one a female, and all were nonsmokers without respiratory symptoms and with normal chest radiographs.

\section{METHODS}

Regional lung function studies were made by profile lung scanning according to the method of Dollery and Gillam (1963). Scans were made with the subjects at rest in the sitting position, the scintillation counters moving vertically up the lungs from base to apex over a distance of about $30 \mathrm{~cm}$ while breath was held at total lung capacity. Regional perfusion was studied after intravenous injection of xenon in solution, ventilation following the inhalation of a single breath of gaseous xenon, and lung volume after equilibration by rebreathing the xenon gas. A fourth scan was made 30 seconds after the perfusion scan, the patient being allowed to breathe normally in the interval between the two. This allowed a further assessment of regional ventilation, that of perfused alveoli. Normally, less than $30 \%$ of the original perfusion activity can be detected in the 'washout' scan. Indices for the distribution of blood flow and ventilation per unit alveolar volume were calculated at $2 \mathrm{~cm}$ intervals up the lung, as described by West (1967). For final display and comparison of the data the scanned lung was divided into three equal zones, the distribution indices for each zone being averaged and expressed as a percentage of the mean distribution index for the whole lung. Further details of the scanning technique are available in previous publications from this laboratory (Brown, Kirk, and Seaton, 1969; Gaziano, Seaton, and Ogilvie, 1970). Tests of overall lung function included measurement of lung volumes and ventilatory capacity, the total lung capacity being obtained by helium dilution (Bates and Christie, 1950). The transfer factor for carbon monoxide was measured by the single breath method of Ogilvie, Forster, Blakemore, and Morton (1957), and arterial $\mathrm{Po}_{2}$ and $\mathrm{PCO}_{2}$ with an Instrumentation Laboratory analyzer (type 313). Standard $6 \mathrm{ft}$ posteroanterior chest radiographs were obtained at each study. Pulmonary artery pressures were measured postoperatively using flow-directed ballooncatheters (Swan et al., 1970).

\section{RESULTS}

The results of tests of overall lung function are seen in the Table. On average lung volumes were reduced about 20 to $25 \%$ by the operation. The transfer factor (TF) fell by $15 \%$ but when expressed in relation to the lung volume at which it was measured (TF/VA) was found not to have changed significantly. Both $\mathrm{Po}_{2}$ and $\mathrm{PcO}_{2}$ increased after surgery but only the rise in $\mathrm{PO}_{2}$ was significant statistically. Regional lung function studies are presented in the form of graphs. (Complete

T A B L E

LUNG VOLUMES, VENTILATORY CAPACITY, TRANSFER FACTOR, AND BLOOD GASES BEFORE AND AFTER PNEUMONECTOMY: MEAN, STANDARD DEVIATION, \% PREDICTED, AND \% CHANGE

\begin{tabular}{|c|c|c|c|c|c|c|c|c|c|}
\hline & $\underset{\text { (litres) }}{\mathrm{VC}}$ & $\underset{\text { (litres) }}{\mathbf{R V}}$ & $\underset{\text { (litres) }}{\text { TLC }}$ & $\begin{array}{l}\text { FEV }_{1} \\
\text { (litres) }\end{array}$ & $\frac{\text { FEV }_{1}}{\text { VC }} \%$ & $\underset{(\mathrm{ml} / \mathrm{min} / \mathrm{mmHg})}{\mathrm{TF}^{\mathbf{1}}}$ & $\underset{\substack{(\mathrm{ml} / \mathrm{min} / \mathrm{mm} \\
\text { per } 1 .)}}{\frac{\mathrm{TF}^{1}}{\mathrm{VAg}}}$ & $\begin{array}{l}\mathbf{P O}_{2}{ }^{1} \\
(\mathbf{m m H g})\end{array}$ & $\underset{(\mathrm{mmHg})}{\mathrm{Pco}_{2}{ }^{1}}$ \\
\hline $\begin{array}{l}\text { Preoperative } \\
\% \text { Predicted }^{2}\end{array}$ & $\begin{array}{r}2.84 \\
\pm 0.60 \\
\text { (71) }\end{array}$ & $\begin{array}{r}2.15 \\
\pm 0.61 \\
(99)\end{array}$ & $\begin{array}{r}4.99 \\
\pm 0.73 \\
\text { (79) }\end{array}$ & $\begin{array}{r}1.77 \\
\pm 0.50 \\
(58)\end{array}$ & 62 & $\begin{array}{c}21 \cdot 27 \\
\pm 4.75 \\
(80)\end{array}$ & $\begin{array}{r}4 \cdot 61 \\
\pm 0 \cdot 80\end{array}$ & $\begin{array}{r}76.33 \\
\pm 11.21\end{array}$ & $\begin{array}{r}34 \cdot 61 \\
\pm 5 \cdot 81\end{array}$ \\
\hline $\begin{array}{l}\text { Postoperative } \\
\% \text { Change }\end{array}$ & $\begin{array}{r}2.13 \\
\pm 0.48 \\
-27\end{array}$ & $\begin{array}{r}1.72 \\
\pm 0.4 \\
-20\end{array}$ & $\begin{array}{r}3.85 \\
\pm 0.69 \\
-23\end{array}$ & $\begin{array}{r}1.47 \\
\pm 0.47 \\
-17\end{array}$ & 69 & $\begin{array}{c}18 \cdot 03 \\
\pm 6 \cdot 58 \\
-15\end{array}$ & $\begin{array}{r}5.05 \\
\pm 1.51 \\
+9.5\end{array}$ & $\begin{array}{r}88.33 \\
\pm 9 \cdot 89 \\
+16\end{array}$ & $\begin{array}{l}38 \cdot 61 \\
+3 \cdot 78 \\
+12\end{array}$ \\
\hline
\end{tabular}

${ }^{1}$ Nine values only.

${ }^{2}$ Cotes (1968). 
data are available on request to the author.) Statistical analysis of dependent results was made using the paired $t$ test and that of independent data with the unpaired $t$ test. In both instances analysis was performed at the $95 \%$ level of confidence.

REGIONAL DISTRIBUTION OF INHALED XENON Figure 1 shows the results of the preoperative studies for the lung not involved by the tumour. On the left-hand side are seen individual results for each lung zone (lower, middle, and upper zones). The right-hand graph compares the mean preoperative ventilation pattern with the mean pattern of ventilation in the 10 volunteers. No significant difference exists between the two.

The postoperative scans are shown in Figure 2.

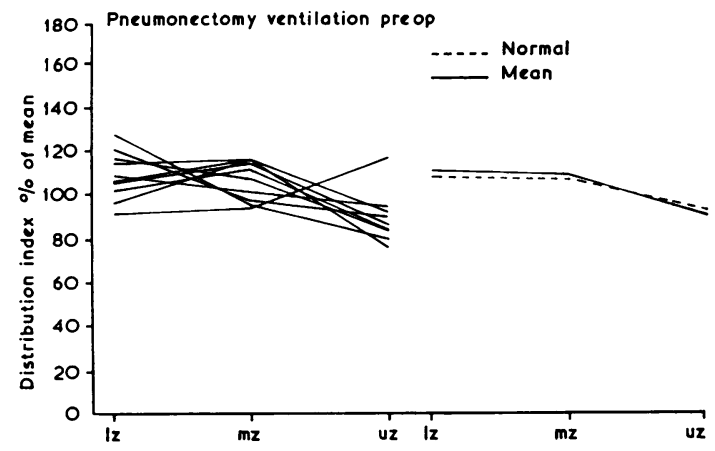

FIG. 1. (Left) Individual ventilation patterns. Preoperative distribution of inhaled xenon between lower, mid, and upper zones for the non-malignant lungs of 10 individual patients. (Right) Mean ventilation patterns. Mean results for the 10 patient lungs compared with the mean results for 10 normal subjects.

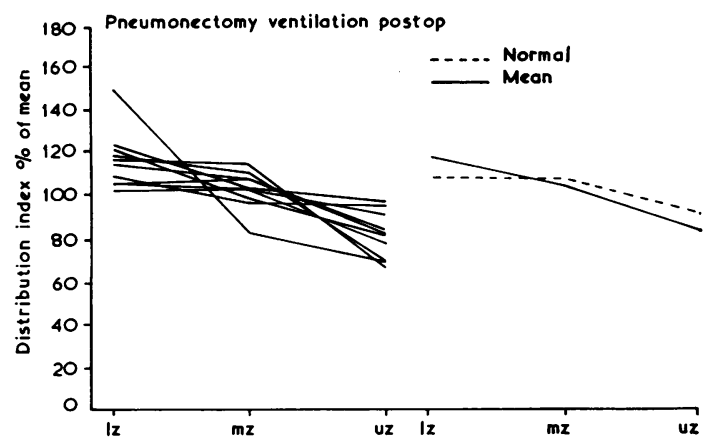

FIG. 2. (Left) Postoperative ventilation patterns: individual results. (Right) Mean postoperative results compared with normals (arranged as in Fig. 1).
The individual results are shown on the left, while the mean is compared to the mean of the scans of 10 normal subjects on the right. No significant difference could be found between the two means.

In Fig. 3 the means of the preoperative and postoperative ventilation scans for the non-malignant lung are compared directly. No difference of significance could be found between them.

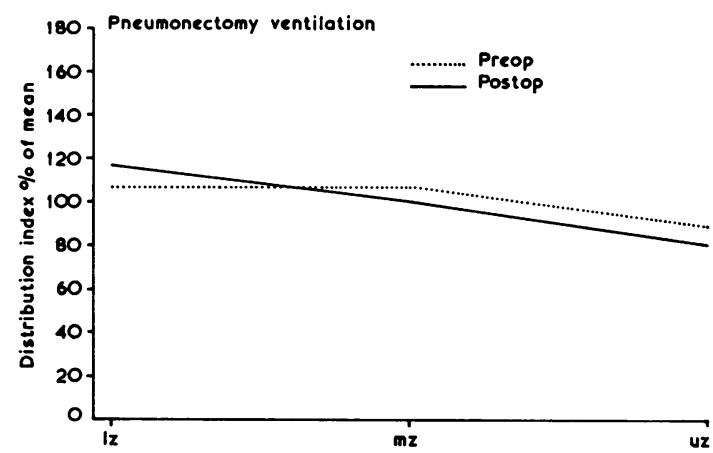

FIG. 3. Comparison of mean preoperative and mean postoperative patterns of ventilation (seen in Figs 1 and 2) for the non-malignant lungs.

WASHOUT OF INJECTED XENON In two preoperative and four postoperative scans poor clearance of injected xenon was seen over the upper zones following the perfusion study. These washout abnormalities were thought to be related not to a disturbance of regional ventilation but to accumulation of xenon in the chest wall, the effect of which is normally most marked at the apices in view of the small volume and low perfusion activity of the underlying lung (Anthonisen, Bass, and Hechscher, 1968). With these exceptions washout studies for the non-malignant lung were normal both before and after surgery.

REGIONAL DISTRIBUTION OF BLOOD FLOW Figure 4 shows the preoperative results, the format being the same as in the previous graphs with individual results on the left-hand side and the mean pattern of perfusion compared with that of the normal subjects on the right. Figure 5 shows the results of the postoperative scans, while Fig. 6 compares the preoperative and postoperative mean patterns of perfusion. Again no significant difference could be detected between the patterns of perfusion of the patients before and after surgery or between those of the patients and of the normal subjects. 


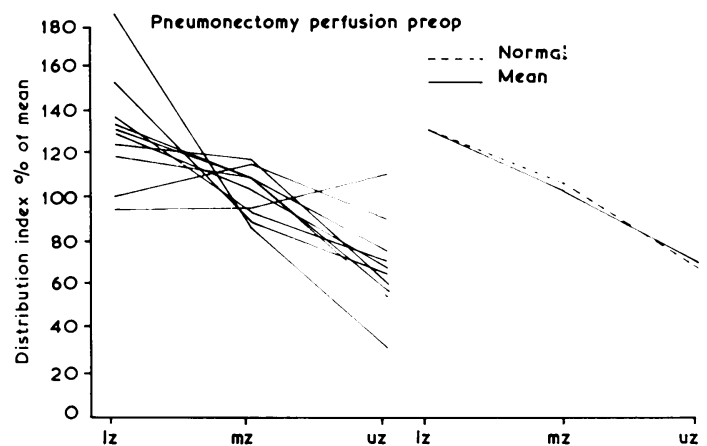

FIG. 4. (Left) Preoperative perfusion patterns: individual results. (Right) Mean preoperative results compared with normals (arranged as in Fig. 1).

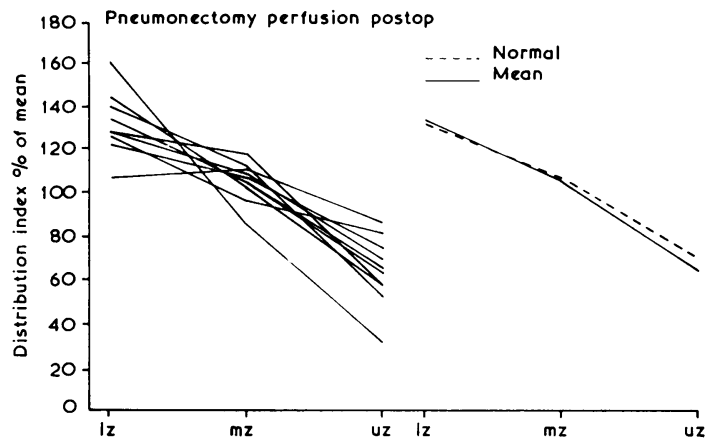

FIG. 5. (Left) Postoperative perfusion patterns: individual results. (Right) Mean postoperative results compared with normals (arranged as in Fig. 1).

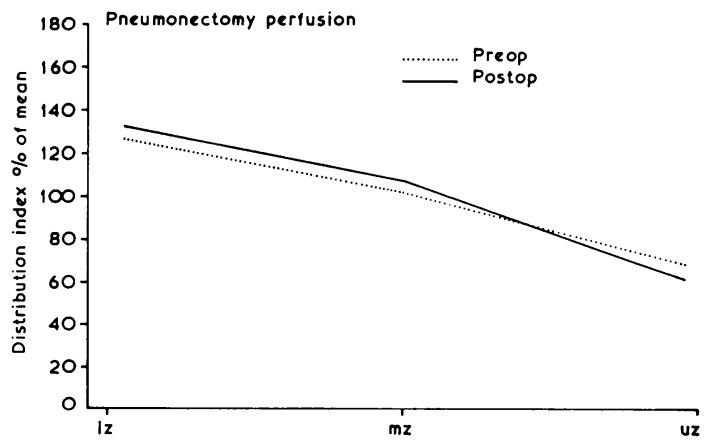

FIG. 6. Mean preoperative and postoperative patterns of perfusion (arranged as in Fig. 3).

PULMONARY ARTERY PRESSURES Postoperative pulmonary artery pressures all fell within normal limits, the highest individual value being $23 / 6$ (mean/15) $\mathrm{mmHg}$.

\section{DISCUSSION}

In the 10 patients studied, removal of one lung did not appear to change the regional distribution of either ventilation or blood flow in the remaining lung. Furthermore, no difference could be detected in the apicobasal gradients of ventilation and perfusion between the normal volunteers and the patients either before or after surgery. Pulmonary artery pressures measured postoperatively were within normal limits. Martin, Cline, and Marshall (1955), using fine catheters, measured lobar alveolar gas concentrations after pneumonectomy and found no difference in lobar ventilation-perfusion ratios between the patients and normals. Anthonisen et al. (1968) studied seven patients undergoing pneumonectomy for either carcinoma or bronchiectasis and found four who appeared to show a postoperative increase in apical perfusion when the scans were compared with those of normal volunteers. No abnormality was found in the distribution of regional ventilation, and the increased apical perfusion was attributed to the development of pulmonary hypertension. However, no preoperative scans were done, and the postoperative studies were made in the first two weeks after surgery. Garnett, Goddard, Fraser, and MacLeod (1968) showed how major perfusion defects may exist on the side not affected by tumour when preoperative lung scans were performed in patients with bronchial carcinoma. These defects, which were not accompanied by radiographic abnormality, were attributed to underlying chronic lung disease. Gaziano et al. (1970), using radioactive xenon, demonstrated a relative decrease in basal ventilation and perfusion in patients with chronic bronchitis and the converse in emphysema. It is apparent, therefore, that differences between a post-pneumonectomy scan and that of a normal volunteer cannot be attributed to the effects of the operation unless a 'control' preoperative study has shown that the differences are not due solely to the presence of pre-existing lung disease.

Perfusion of the upright lung may become more evenly distributed with relatively small increases in pulmonary blood flow on exercise and in left to right cardiac shunts (Dollery et al., 1961; Bryan et al., 1964). A sudden doubling of blood flow after pneumonectomy might be expected to have similar results. Friend (1954) warned how any comparison of pulmonary function before and after lung resection was complicated by the effect of the tumour itself on the preoperative indices. Tests of regional lung function are no 
exception. Wagner, Lopez-Majano, Tow, and Langan (1965), using radioactive albumen, demonstrated a reduction of blood flow in the tumour-bearing lung of patients with hilar bronchial carcinoma. In the present series, the affected lungs received an average of only $25 \%$ of the total pulmonary blood flow. Pneumonectomy would therefore increase blood flow to the residual lung by only $33 \frac{1}{3} \%$ rather than $100 \%$, the carcinoma being responsible for slow diversion of blood flow to the unaffected side prior to surgery. Comparison of the preoperative lung scans with those of the normals did not reveal any change in perfusion distribution resulting from this preoperative readjustment of perfusion.

Measurement of the transfer factor for carbon monoxide may help in the preoperative assessment of patients with carcinoma of the bronchus by reflecting the extent of lung involvement by the tumour and the integrity of the non-involved lung (Zohman and Williams, 1959). Bates, Macklem, and Christie (1971) suggested that the transfer factor may be sensitive to the extent of upper lobe perfusion, an increase in both occurring, for example, on exercise. McIlroy and Bates (1956) found that the transfer factor, when related to the lung volume at which it is measured (TF/ VA), changes little after pneumonectomy. In the present series of patients, absence of increase in apical perfusion postoperatively was accompanied by a lack of significant change in TF/VA.

Thus it appears that the 10 patients studied have been able to tolerate increased amounts of perfusion in the non-malignant lung that amounted eventually to a doubling of pulmonary blood flow postoperatively when the entire cardiac output passed through the residual lung. This extra flow was accommodated without call on the 'apical reserve' and without the development of pulmonary arterial hypertension. The increase in overall ventilation of the residual lung likewise did not result in any change in the distribution of regional ventilation.

In assessing the significance of these findings the original criteria for selection of these patients should be borne in mind so as to dispel the notion that only subjects with unusually good overall lung function were chosen. Patients were, in the main, referred directly to one of six thoracic surgeons, each differing in aggressiveness of approach to the disease and in willingness to operate on subjects with poor pulmonary function. Many patients were rejected for surgical treatment on the basis of either clinical and radiographic examination or because of abnormal spirometry. All subjects who passed this initial screening and were acceptable to the surgeon as candidates for operation were eligible for inclusion in the study. The 10 pneumonectomy patients in whom full preoperative and postoperative studies were performed had overall pulmonary function similar to that seen in life-long smokers of comparable age, the mean $\mathrm{FEV}_{1} / \mathrm{FVC}$ before surgery being $62 \%$, and four patients having values below $60 \%$ (i.e., significant airways obstruction). The $\mathrm{PCO}_{2}$ was elevated above $45 \mathrm{mmHg}$ in three subjects. There is nothing to suggest that these 10 patients differed significantly from other patients surviving pneumonectomy in the same or similar surgical units.

Analysis of the preoperative perfusion scans for the 10 patients showed, as mentioned before, significant impairment of perfusion in the tumour-bearing lung, the affected side receiving on average only $25 \%$ of the total pulmonary blood flow. One patient, however, despite a hilar carcinoma, retained the normal 50/50 partitioning of ventilation and perfusion between the two lungs. In this instance pneumonectomy must have resulted in a sudden large increase in blood flow to the residual lung. Comparison of the preoperative and postoperative perfusion scans revealed an increase in apical perfusion postoperatively, although this was not statistically significant. The patient's course after surgery was uncomplicated, his preoperative pulmonary function being good. If, however, pulmonary reserves had been markedly reduced before surgery, the extra circulatory and respiratory demands on the residual lung postoperatively might have been sufficient to precipitate cardiorespiratory failure.

Thus it seems that most patients with lung cancer are able to adapt gradually to increasing blood flow in the non-malignant lung as increasing restriction of perfusion takes place on the tumour-bearing side. In these cases pneumonectomy involves the removal of the relatively functionless lung and results in little physiological disturbance. Occasional subjects may be seen, however, in whom there is a combination of normal blood flow on the side of the tumour and reduced pulmonary reserve. Pneumonectomy in these patients, by doubling blood flow through an inadequate contralateral lung, may precipitate pulmonary hypertension and right heart failure. The measurement of regional as well as overall lung function preoperatively may help to anticipate this complication. 
I should like to thank the consultant cardiothoracic surgeons at Broadgreen Hospital for allowing me to study their patients, Dr. C. M. Ogilvie for constant encouragement and advice, and Drs. W. K. C. Morgan and N. L. Lapp for their helpful comments. Dr. C. C. Evans, Miss S. Williams, Mrs. M. Deakin, and Miss D. Pollard provided invaluable technical assistance, and Mrs. Linda Smith was kind enough to type the manuscript.

\section{REFERENCES}

Anthonisen, N. R., Bass, H., and Hechscher, T. (1968). ${ }^{123} \mathrm{Xe}$ studies of patients after pneumonectomy. Scandinavian Journal of Respiratory Diseases, 49, 81.

Ball, W. C., Jr., Stewart, P. B., Newsham, L. G. S., and Bates, D. V. (1962). Regional pulmonary function studied with Xenon ${ }^{123}$. Journal of Clinical Investigation, 41, 519.

Bates, D. V. and Christie, R. V. (1950). Intrapulmonary mixing of helium in health and in emphysema. Clinical Science, 9, 17.

- Macklem, P. T., and Christie, R. V. (1971). Respiratory Function in Disease, 2nd edition, p. 78. Saunders, Philadelphia.

Björk, V. O. (1953). Cardiopulmonary function tests. Journal of Thoracic Surgery, 26, 67.

Brown, I. K., Kirk, F., and Seaton, A. (1969). A scanner stand for pulmonary function studies. British Journal of Radiology, 42, 545.

Bryan, A. C., Bentivoglio, L. G., Beerel, F., MacLeish, H., Zidulka, A., and Bates, D. V. (1964). Factors affecting regional distribution of ventilation and perfusion in the lung. Journal of Applied Physiology, 19, 395.

Carlens, E., Hanson, H. E., and Nordenström, B. (1951). Temporary unilateral occlusion of the pulmonary artery. Journal of Thoracic Surgery, 22, 527.

Cournand, A., Himmelstein, A., Riley, R. L., and Lester, C. W. (1947). A follow-up study of the cardiopulmonary function in four young individuals after pneumonectomy. Journal of Thoracic Surgery, 16, 30.

- , Riley, R. L., Himmelstein, A., and Austrian, R. (1950). Pulmonary circulation and alveolar ventilation-perfusion relationships after pneumonectomy. Journal of Thoracic Surgery, 19, 80.

Cotes, J. E. (1968). Lung Function, 2nd ed., p. 384. Blackwell, Oxford.

Dawson, A., Kaneko, K., and McGregor, M. (1965). Regional lung function in patients with mitral stenosis studied with Xenon ${ }^{133}$ during air and oxygen breathing. Journal of Clinical Investigation, 44, 999.

Denolin, H. (1961). Contribution à l'étude de la circulation pulmonaire en clinique. La pneumonectomie chez l'homme. Acta Cardiologica, Supplement 10, 113.
Dollery, C. T. and Gillam, P. M. S. (1963). The distribution of blood and gas within the lungs measured by scanning after administration of ${ }^{133} \mathrm{Xe}$. Thorax, 18, 316.

and West, J. B. (1960). Regional uptake of radioactive oxygen, carbon monoxide and carbon dioxide in the lungs of patients with mitral stenosis. Circulation Research, 8, 765.

-, Wilcken, D. E. L., Goodwin, J. F., and Hugh-Jones, P. (1961). Regional pulmonary blood flow in patients with circulatory shunts. British Heart Journal, 23, 225.

Friend, J. (1954). Respiratory insufficiency after pneumonectomy. Lancet, 2, 260.

Garnett, E. S., Goddard, B. A., Fraser, H. S., and MacLeod, W. M. (1968). Lung perfusion patterns in carcinoma of bronchus. British Medical Journal, 2, 209.

Gaziano, D., Seaton, A., and Ogilvie, C. M. (1970). Regional lung function in patients with obstructive lung diseases. British Medical Journal, 2, 330.

Graham, E. A. and Singer, J. J. (1933). Successful removal of an entire lung for carcinoma of the bronchus. Journal of the American Medical Association, 101, 1371.

Harrison, R. W., Adams, W. E., Long, E. T., Burrows, B., and Reimann A. (1958). The clinical significance of cor pulmonale in the reduction of cardiopulmonary reserve following extensive pulmonary resection. Journal of Thoracic Surgery, 36, 352.

Martin, C. J., Cline, F., Jr., and Marshall, H. (1955). Lobar alveolar gas concentration after pneumonectomy. Journal of Clinical Investigation, 34, 875.

McIlroy, M. B. and Bates, D. V. (1956). Respiratory function after pneumonectomy. Thorax, 11, 303.

Mendelsohn, H. J., Zimmerman, H. A., and Adelman, A. (1950). A study of pulmonary hemodynamics during pulmonary resection. Journal of Thoracic Surgery, 20, 366.

Ogilvie, C. M., Forster, R. E., Blakemore, W. S., and Morton, J. W. (1957). A standardized breath holding technique for the clinical measurement of the diffusing capacity of the lung for carbon monoxide. Journal of Clinical Investigation, 36, 1.

Peters, R. M., Roos, A., Black, H., Burford, T. H. and Graham E. A. (1950). Respiratory and circulatory studies after pneumonectomy in childhood. Journal of Thoracic Surgery, 20, 484.

Seaton, A. (1971). M. D. Thesis, University of Cambridge.

Swan, J. J. C., Ganz, W., Forrester, J., Marcus, H. Diamond, G. and Chonette, D. (1970). Catheterization of the heart in man with use of a flowdirected ballon-tipped catheter. New England Journal of Medicine, 283, 447.

Ueda, H., Iio, M., and Kaihara, S. (1964). Determination of regional pulmonary blood flow in various cardiopulmonary disorders. Japanese Heart Journal, 5, 431. 
Wagner, H. N., Jr., Lopez-Majano, V., Tow, D. E., and Langan, J. K. (1965). Radioisotope scanning of lungs in early diagnosis of bronchogenic carcinoma. Lancet, 1, 344.

West, J. B. (1967). The use of radioactive materials in the study of lung function. Medical Monograph No. 1. UKAEA, The Radiochemical Centre, Amersham, England.

Dollery, C. T., and Naimark, A. (1964). Distribution of blood flow in isolated lung; relation to vascular and alveolar pressures. Journal of Applied Physiology, 19, 713.
Wiederanders, R. E., White, S. M., and Saichek, H. B. (1964). The effect of pulmonary resection on pulmonary artery pressures. Annals of Surgery, 160, 889.

Zohman, L. R. and Williams, M. H., Jr. (1959). Clinical usefulness of measurement of the diffusing capacity of the lung. New York State Journal of Medicine, 59, 453.

Requests for reprints to: Dr. D. Russell Hall, Cardiopulmonary Division, West Virginia University Medical Center, Morgantown, West Virginia 26506, USA. 